\title{
Le renoncement au féminin. Couvents et nonnes dans le bouddhisme tibétain
}

Doctorat en ethnologie, sous la direction de Anne-Marie Blondeau, Université Paris Ouest Nanterre-La Défense, soutenu le 13 décembre 2010.

Nicola Schneider

\section{(2) OpenEdition}

Édition électronique

URL : http://journals.openedition.org/assr/24601

DOI : 10.4000/assr.24601

ISSN : $1777-5825$

Éditeur

Éditions de l'EHESS

\section{Édition imprimée}

Date de publication : 30 décembre 2012

Pagination : 309-358

ISSN : 0335-5985

\section{Référence électronique}

Nicola Schneider, « Le renoncement au féminin. Couvents et nonnes dans le bouddhisme tibétain », Archives de sciences sociales des religions [En ligne], 160 | octobre-décembre 2012, mis en ligne le 14 mars 2013, consulté le 01 mai 2019. URL : http://journals.openedition.org/assr/24601

Ce document a été généré automatiquement le 1 mai 2019.

(c) Archives de sciences sociales des religions 


\section{Le renoncement au féminin. Couvents et nonnes dans le bouddhisme tibétain ${ }^{1}$}

Doctorat en ethnologie, sous la direction de Anne-Marie Blondeau, Université Paris Ouest Nanterre-La Défense, soutenu le 13 décembre 2010.

\section{Nicola Schneider}

1 Les travaux antérieurs d'autres chercheurs ont montré que les nonnes tibétaines sont confrontées à un grand nombre de discriminations : elles n'ont pas accès à la hiérarchie cléricale, ne jouissent pas des mêmes faveurs économiques que les moines et, jusque très récemment, elles n'avaient droit qu'à une éducation sommaire. De ce fait, elles occupent une place subalterne dans le système monastique tibétain. Dès lors, comment peut-on expliquer l'attrait qu'exerce la vie monastique sur beaucoup de femmes aujourd'hui?

2 Cette thèse, qui s'appuie sur l'étude ethnographique de deux monastères de femmes, l'un situé au Tibet même (Mi nyag) et l'autre en terre d'exil (Inde, Dharamsala), cherche à rendre compte des changements en cours et à comprendre la recrudescence du monachisme féminin qui a accompagné le renouveau monastique depuis la fin de la Révolution culturelle en Chine. Obtenus grâce à une méthodologie qui emprunte à la fois à l'anthropologie, à l'histoire et à la tibétologie, les résultats sont présentés en trois grandes parties.

3 La première est consacrée au contexte historique du monachisme féminin. Fondée sur des sources écrites, en tibétain et en langues occidentales et sur des entretiens, cette partie présente successivement la fondation du monachisme féminin au Tibet, les institutions anciennes et les conditions de vie des nonnes à cette époque. Elle conclut sur les événements qui se sont produits depuis l'occupation du Tibet par la Chine et qui ont entraîné un grand nombre de bouleversements.

4 La deuxième partie rend compte du mode de vie monastique actuel dans les deux couvents étudiés à travers une ethnographie détaillée. Sont présentés successivement, 
pour chaque communauté, sa fondation, l'organisation, le fonctionnement de la hiérarchie, les aspects économiques, le réseau local et/ou international et les activités religieuses et extra-religieuses des nonnes. Ces deux monastères mettent l'accent sur l'éducation des nonnes, mais de façon distincte : à Tashi Gönsar au Tibet, c'est au travers des enseignements et des initiations périodiques et à Dolma Ling, grâce à un programme d'études bouddhiques supérieures. Ce dernier devrait permettre aux femmes d'obtenir, un jour, le diplôme et titre de "docteur en philosophie traditionnelle bouddhique » (dge bshes), autrefois réservé aux moines. Ces deux monastères proposent aussi aux nonnes qui le souhaitent d'apprendre un métier qui corresponde à leurs aspirations religieuses.

5 La troisième partie examine d'abord les raisons qui poussent des jeunes femmes à s'engager dans ce mode de vie singulier. Les nonnes mettent elles-mêmes en avant leurs motivations religieuses, mais force est de constater que pour nombre d'entre elles, des motivations d'ordre sociologique jouent également un rôle important dans ce choix: entrer en religion permet d'échapper au mariage - souvent arrangé dans les milieux ruraux d'où est originaire la majorité des nonnes -, à la procréation et au travail féminin, considéré comme très dur. De plus, être nonne procure un certain prestige puisque cela permet de choisir son éducation, qui est tibétaine dans les monastères, mais souvent chinoise dans les écoles, et de travailler à la préservation de la culture et de l'identité tibétaines. Ainsi, entrer en religion est aussi un acte politique, voire de résistance.

6 La section suivante aborde les questions de l'intégration dans la communauté monastique, du choix de la communauté et du lama, ainsi que les étapes successives qui permettent de devenir nonne. Depuis ces vingt dernières années, une controverse a vu le jour puisque les nonnes, contrairement aux moines, ne peuvent recevoir l'ordination plénière dans la tradition tibétaine. En effet, une lignée de nonnes pleinement ordonnées est nécessaire pour effectuer le rituel, lignée qui n'a jamais existé au Tibet. De nos jours, certaines nonnes tibétaines, poussées par leurs consœurs occidentales, voudraient instaurer l'ordination plénière pour les femmes, mais elles se heurtent, pour l'instant, au clergé qui reste majoritairement opposé à cette idée.

7 Finalement, dans le dernier chapitre, sont analysées les causes qui entraînent de nos jours de nombreuses nonnes à quitter la vie monastique et ceci plus particulièrement en exil. L'une d'elles est une maladie, appelée "maladie de femmes » (mo nad) - symptôme des difficultés et tensions de la vie monacale -, qui, selon les croyances tibétaines, peut provoquer la mort des femmes qui pratiquent la chasteté.

8 En conclusion, on peut dire que la vie monacale met à la disposition des femmes un choix d'activités qui n'existe pas pour nombre de Tibétaines issues du milieu rural où la coutume dicte encore que les filles reprennent le travail de leur mère puis celui de leur belle-mère. Le monastère attire donc par son offre et crée de nouvelles opportunités pour ces femmes, leur permettant de réaliser un grand nombre de projets individuels et collectifs. Cependant, il n'est pas sûr que la recrudescence du monachisme féminin perdurera dans le temps comme le montre la situation en exil où, parallèlement à l'accès à l'éducation et à une amélioration de la condition féminine, le nombre de vocations commence à diminuer et on observe un abandon de la vie monastique par un nombre de plus en plus grand de nonnes. 


\section{NOTES}

1. Publié auparavant dans «Nicola Schneider. Le renoncement au féminin. Couvents et nonnes dans le bouddhisme tibétain ", Études mongoles et sibériennes, centrasiatiques et tibétaines, 42, 2011, mis en ligne le 20 décembre 2011. URL : http://emscat.revues.org/ index1943.html

\section{AUTEUR}

\section{NICOLA SCHNEIDER}

schneidernicola@hotmail.com 